\title{
The Influence of Base Layer Thickness in Flexible Pavements
}

\author{
Muhammed Abdul Sada Hadi \\ Department of Civil Engineering \\ University of Baghdad \\ Baghdad, Iraq \\ m.hadi1901m@coeng.uobaghdad.edu.iq
}

\author{
Mohannad H. Al-Sherrawi \\ Department of Civil Engineering \\ University of Baghdad \\ Baghdad, Iraq \\ dr.mohannad.al-sherrawi@coeng.uobaghdad.edu.iq
}

\begin{abstract}
Flexible pavement design and analysis were carried out in the past with semi-experimental methods, using elastic characteristics of pavement layers. Due to the complex interferences between various layers and their time consumption, the traditional pavement analysis, and design methods were replaced with fast and powerful methods including the Finite Element Method (FEM) and the Discrete Element Method (DEM). FEM requires less computational power and is more appropriate for continuous environments. In this study, flexible pavement consisting of 5 layers (surface, binder, base, subbase, and subgrade) had been analyzed using FEM. The ABAQUS (6.14-2) software had been utilized to investigate the influence of the base layer depth on vertical stresses and displacements. Three different thicknesses were adopted $(10,20$, and $30 \mathrm{~cm})$ with constant other pavement layer thicknesses. The results of this study showed that the stress levels at the top of the base layer increased by about $37 \%$ when the thickness of this layer increased from $10 \mathrm{~cm}$ to $30 \mathrm{~cm}$, while the stress levels at the top of the subbase layer decreased by about $64 \%$. When the base layer increased from 10 to 20 , from 20 to 30 , and from 10 to $30 \mathrm{~cm}$ the vertical displacement decreased by $18 \%, 24 \%$, and $37 \%$ respectively.
\end{abstract}

Keywords-flexible pavement; ABAQUS; base thickness; finite element method

\section{INTRODUCTION}

Standard flexible pavements with surface of Asphalt Concrete $(\mathrm{AC})$ are used worldwide. The different layers of the flexible pavement structure have various strength and deformation properties, which make difficult to analyze the system layers [1]. Factors such as material properties, geometry of pavement structures, environment, traffic loading and construction practices affect the pavements. Furthermore, vehicle characteristics, load axle, and wheel configuration may cause damage to the pavements [2]. If the induced strains due to the external load are relatively small, stresses and deformations are usually estimated using the theory of elasticity. Semi-analytical and analytical solutions are available to analyze the behavior of elastic layered pavements subjected to surface loads. In solutions concerning the analysis of the pavement layer system under traffic load, the pavement layers are considered homogeneous, isotropic, and linear elastic [2].
Finite Element Method (FEM) is used to simulate several pavement problems that cannot be modelled using the elastic multi-layer theory. ABAQUS is commercial Finite Element (FE) modeling software. The ABAQUS (6.14-2) software package of engineering analysis is used world-wide to simulate the physical response from loading, contact, temperature, impact, and other conditions of the environment of structures and solid organisms [3]. The software can manage the assembly of parts (including flexible pavement layers, i.e. surface, binder, base-course, sub-base, and subgrade layer) and define the interactions between these layers and the appropriate boundary conditions. Finally, it can find the value of maximum stress and the displacement for all pavement layers.

Several studies of the behavior of flexible floors in recent years have studied three-dimensional (3D) FE models. Authors in [4] employed the discretization of a 3-layer flexible pavement system subject to various loading types using the FE technique. Three layers of the same elastic module have been applied to turn the three layer systems into equivalent, simpler single-layer systems in the analysis. The utility of the 2dimensional FE ANSYS program analytics has been described in [5], in order to examine the influence of the variation of thickness on crucial parameters of distinct component layers. It was observed that the tensile strain at the base of the asphalt layer and the compressive strain above the subgrade layer decline, when the depth of the asphalt layer increases. The authors also discussed the utility of FEM analysis for the exploration of the bituminous pavement characteristic sensitivity analysis. One aspect of the analysis was to check for the hypothesized trials of the sensitivity of the axissymmetric horizontal dimension. Mesh refinement study was also conducted on the selected thickenings and material properties of various layers. Authors in [6] studied the effect of increasing axle load and the variation of pavement modulus on the overall pavement life. The results showed that tensile and compressive strain increased when the axle load increased and decreased when the asphalt layer modulus increased. Authors in [7] used ABAQUS to evaluate the stress and vertical displacement on the top of the surface layer in multi-layer flexible pavements under static loading. It was observed that raised thickness of the pavement surface layer led to reduction of the deformation and stress levels. 


\section{FINITE ELEMENT MODELING OF FLEXIBLE PAVEMENT}

One of the most effective techniques used to simulate the response of different structural engineering challenges is the FEM. It has become the most extensively utilized technique in both academic and industrial numerical simulations [8]. Over the last three decades, substantial advancements in computer programs and FE techniques have made many commonly used 3D structural studies more affordable. The current research models and investigates the behavioral reaction of the pavement system using the ABAQUS 6.14-2 package [9]. Solid structural 3D pavement analysis utilizing the linear, general purpose brick element C3D8R has been adopted in the modeling process. Small elements are necessary to capture a tress concentrated at the structural limit [3].

\section{MATERIALS AND METHODS}

\section{A. Pavement Model}

3D FE was used to model the surface, binder, base course, subbase, and subgrade, all of which may be considered as closed systems of numerous layers. In the present work, a conventional pavement section was considered, consisting of bituminous layers (surface, binder, base), subbase, and subgrade to study the effect of base layer thickness on the flexible pavement layers' performance, starting from $10 \mathrm{~cm}$ with an increment of $10 \mathrm{~cm}$ with fixed surface, binder, subbase, and subgrade depth thickness $(4,7.5,20$, and $250 \mathrm{~cm}$ respectively), as shown in Table I.

\begin{tabular}{|c|c|c|c|c|}
\hline \multirow{2}{*}{ Layer } & \multirow{2}{*}{$\begin{array}{l}\text { Layer } \\
\text { name }\end{array}$} & \multicolumn{3}{|c|}{ Thickness (cm) } \\
\hline & & Case 1 & Case 2 & Case 3 \\
\hline 1 & Surface & 4 & 4 & 4 \\
\hline 2 & Binder & 7.5 & 7.5 & 7.5 \\
\hline 3 & Base course & 10 & 20 & 30 \\
\hline 4 & Subbase & 20 & 20 & 20 \\
\hline 5 & Subgrade & 250 & 250 & 250 \\
\hline
\end{tabular}

The pavement geometry has the following dimensions: $500 \mathrm{~cm}$ in the $\mathrm{y}$ - and the $\mathrm{x}$-axes and $300 \mathrm{~cm}$ in the $\mathrm{z}$-axis. Only a quarter of the sample was used by using the 3D axissummitry property to reduce effort and time. The pavement geometry with the model can be seen in Figures 1, 2. A standard single axle load of a dual tire of $80 \mathrm{kN}$ was considered.
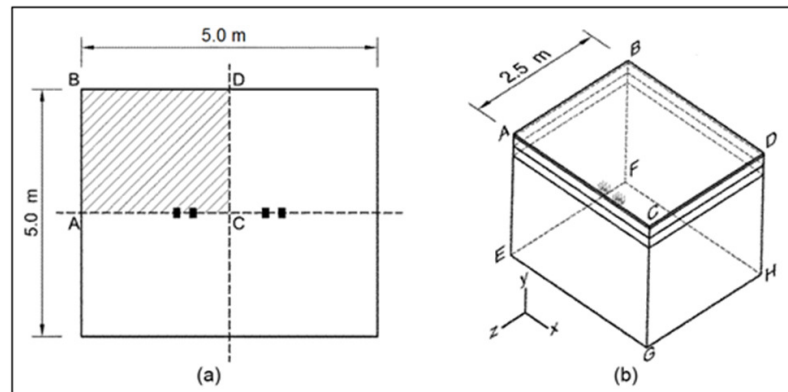

Fig. 1. Geometry model of the flexible pavement: (a) top view, (b) a quarter analytical model.

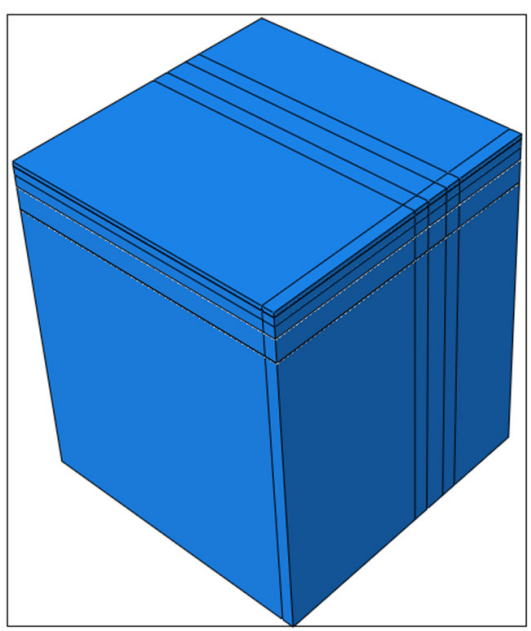

Fig. 2. The 3D multilayer model.

\section{B. Material Properties}

The layers' material characterizations listed in Table II were used in the FE program for flexible pavement models.

TABLE II. MATERIAL PROPERTIES FOR ROAD LAYERS [10]

\begin{tabular}{|c|c|c|}
\hline Layer & Modulus of elasticity (E), kpa & Poisson ratio \\
\hline Surface & 2689000 & 0.35 \\
\hline Binder & 2206000 & 0.35 \\
\hline Base & 1655000 & 0.35 \\
\hline Subbase & 110000 & 0.40 \\
\hline Subgrade & 35000 & 0.499 \\
\hline
\end{tabular}

\section{Contact Area and Tire Presure}

The print area of the tire can be represented by two semicircles and a rectangle [11]. This shape is converted to a rectangle with an area of $0.5227 \times \mathrm{L}^{2}$. The contact area has dimensions of $0.202 \mathrm{~m}$ and $0.14 \mathrm{~m}$. In research and computing applications, even such a simple model is often applied as a uniformly distributed load over a circular or rectangular area [11].

\section{Wheel Load Caracterization}

The wheel load is a standard axle loading simplified in a rectangular uniform surface charge treated as a single axis dual tire [11]. The standard has one axle, dual tires, and contact pressure equivalent to the pressure of the tire. The pressure of the tire is $750 \mathrm{kPa}$ and the overall load of the axle is $80 \mathrm{kN} \mathrm{[6].}$ The load zone established by the vehicle load is illustrated in Figure 3. The width of the print zone is $14 \mathrm{~cm}$ for each tire, which is the same as the width of uniformly distributed surface loads and the length of the print tire is $20.3 \mathrm{~cm}$.

\section{E. Boundary Conditions}

Boundary conditions have a major effect on the prediction of the model response. The lower surfaces against all degrees of freedom are assumed to be entirely fixed for boundary conditions [12]. The edges can move in the vertical (y-) direction for all the geometry models of the pavement. In FE analysis, no movement is considered in the horizontal directions for the four sides of the model. These boundary 
conditions were chosen in order to simulate the real boundary conditions [13] as shows in Figure 5.

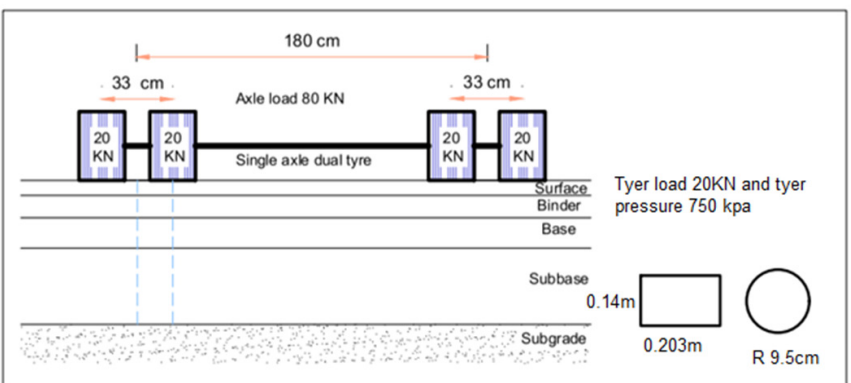

Fig. 3. Standard axle load, critical loads, and loading form.

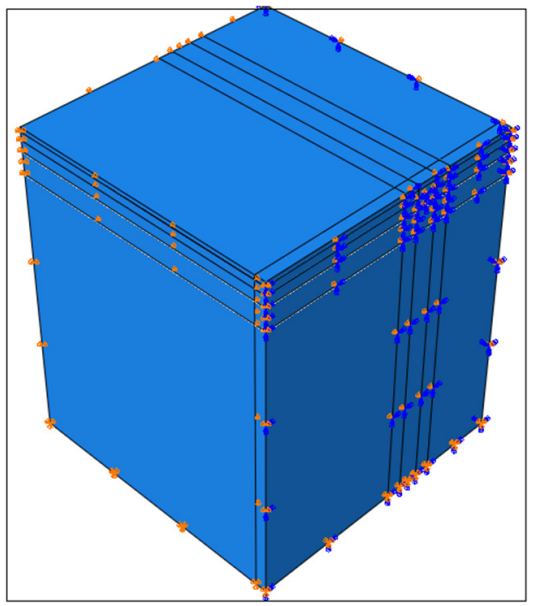

Fig. 4. The boundary conditions of the model.

\section{F. Interaction Modeling Techniques}

The Interaction module is employed to simulate the contact surface between the asphalt and the foundation layers [3]. The interaction between the sections of the model with ABAQUS needs to be established in order to define the interaction surfaces.

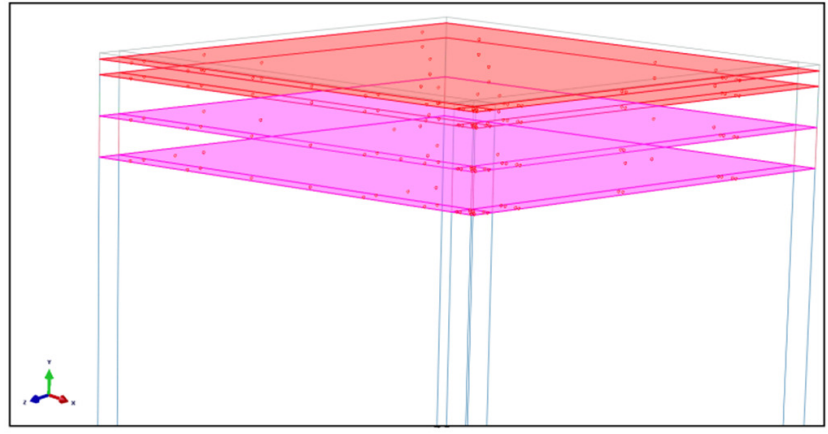

Fig. 5. The interaction layer used in the model.

There are numerous contact formulations and standards in ABAQUS, for the modeling of the interaction between layers. The contact between two flexible or deformable and rigid surfaces is referred to as surface-to-surface contact. The degrees of freedom between the mode areas are utilized in the interaction module constraint and the limitations can be suppressed and repeated to alter the analytical model. The definition of contact is shown in Figure 5. Finally, the ABAQUS interaction module simulates the interaction of several layers of the pavement (surface and binder, binder and base, base and subbase, and subgrade and base) with the tire contact.

\section{G. Mesh Size Distribution in The Model}

Figure 6 presents the FE mesh of the model. The average mesh size under the wheel path is about $5 \mathrm{~cm}$ and the total number of elements is more than 20000. Using a finer mesh near the load when modeling the pavement block as a FE model increases the accuracy of the results [14].

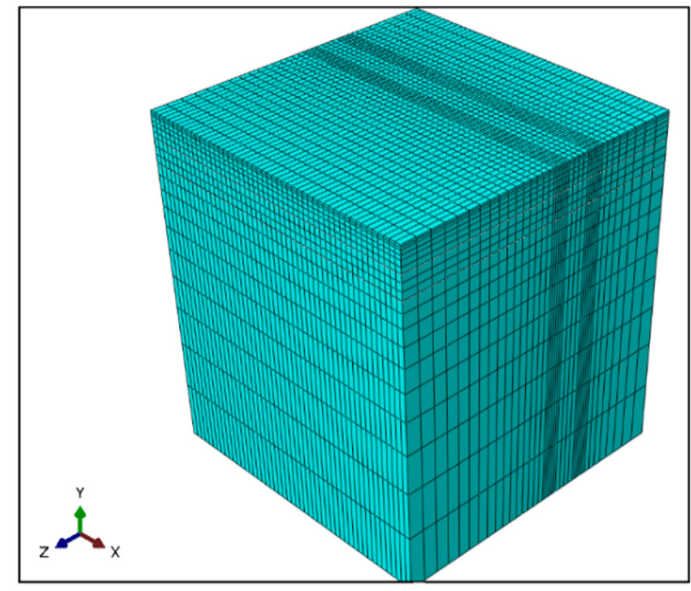

Fig. 6. Mesh size distribution for the 3D dual tire model.

\section{RESULTS AND DISCUSSION}

Stresses and displacements generated in pavement layers and interfaces due to the effect of wheel loads are some of the most primary considered elements in the design of flexible pavements. The obtained results of stresses and their vertical distribution from the FE model analysis adopted in this research are presented in Figures 7-12.

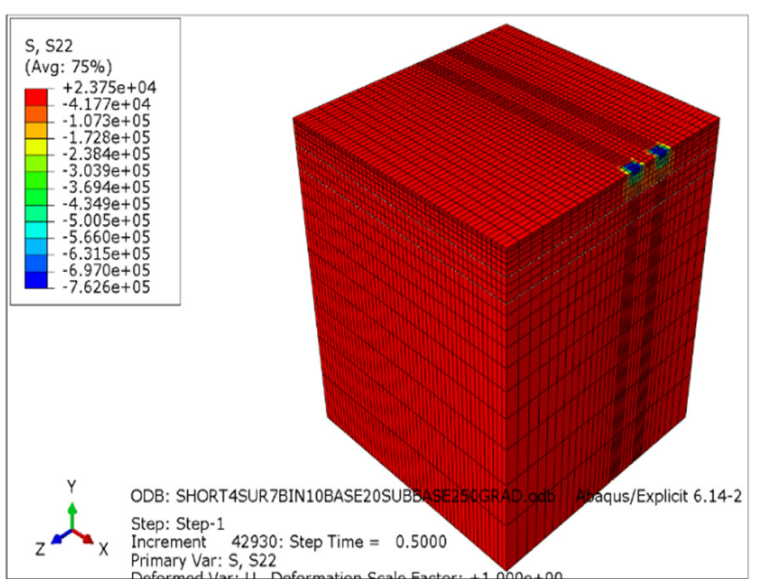

Fig. 7. Horizontal stress $(\sigma \mathrm{xx})$ distribution within pavement layers, case 1 . 


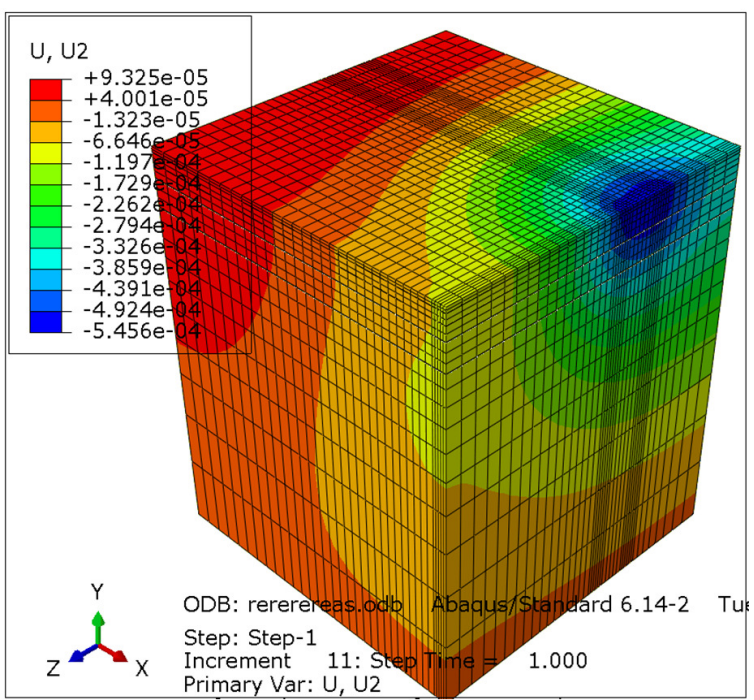

Fig. 8. Vertical displacement distribution within pavement layers, case 1.

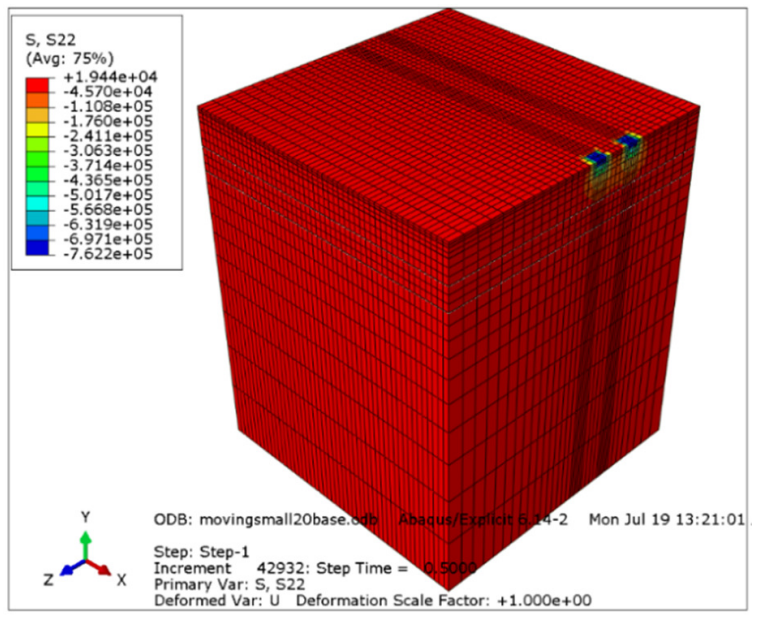

Fig. 9. Horizontal stress $(\sigma \mathrm{xx})$ distribution within pavement layers, case 2.

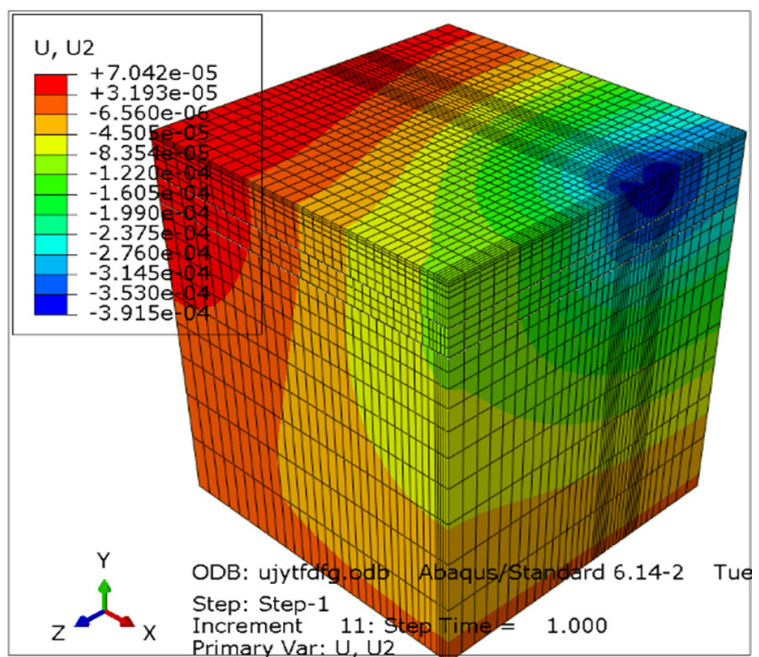

Fig. 10. Vertical displacement distribution within pavement layers, case 2.

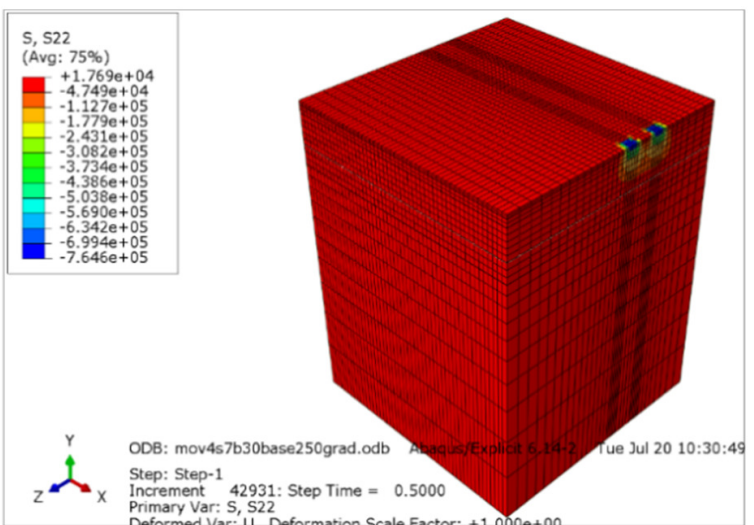

Fig. 11. Horizontal stress $(\sigma \mathrm{xx})$ distribution within pavement layers, case 3.

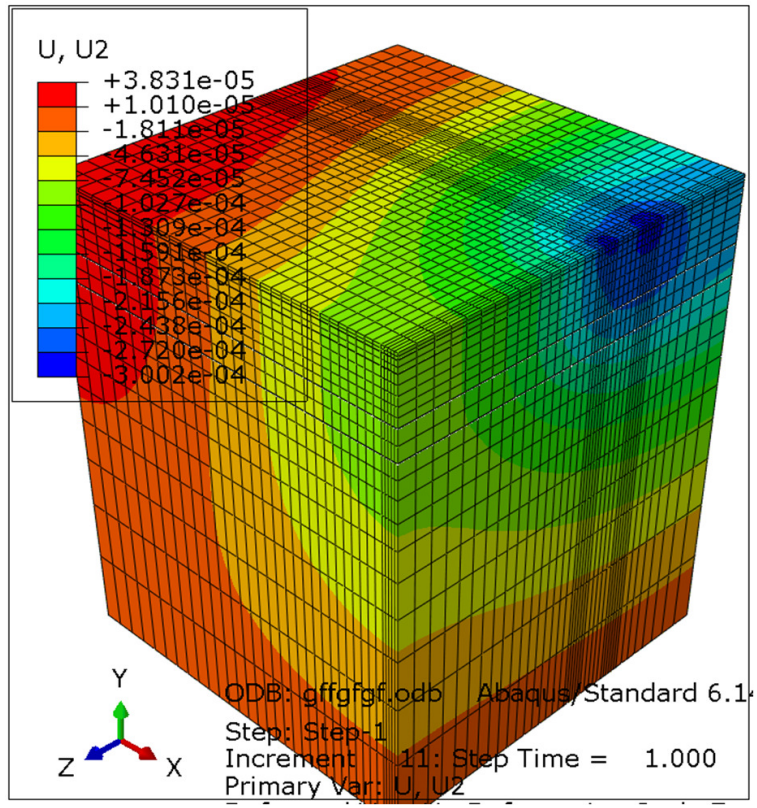

Fig. 12. Vertical displacement distribution within pavement layers, case 3.

The distribution of vertical stresses $(\sigma 22)$ in the pavement system is shown in Table III. In case 1, a maximum vertical stress of $750 \mathrm{kPa}$ is concentrated on the top of the surface layer under the tire print. It is reduced to $579.91 \mathrm{kPa}$ at the top of the binder layer, which is about $77.7 \%$ of the applied pressure. At the top of the base layer, the stress is reduced to a value of $195.63 \mathrm{kPa}$ (about $26 \%$ of the applied tire pressure). It decreases to $40.547 \mathrm{kPa}$ and $20.071 \mathrm{kPa}$ (about $5 \%$ and $2.5 \%$ of the applied tire pressure) on the top of the subbase and the subgrade layer respectively.

In case 2 , the vertical stress is reduced to $600.33 \mathrm{kPa}$, $240.39 \mathrm{kPa}, 22.39 \mathrm{kPa}$, and $13.14 \mathrm{kPa}$ at the top of the binder, base, subbase, and subgrade layers (about 80\%, 32\%, 2.9\% and $1.6 \%$ of the applied pressure respectively).

In case 3 , the vertical stress is reduced to $606.03 \mathrm{kPa}$, $268.87 \mathrm{kPa}, 14.075 \mathrm{kPa}$, and $9.4576 \mathrm{kPa}$ at the top of the binder, base, subbase, and subgrade layers (about 81\%, 38\%, 1.7\% and $1.1 \%$ of the applied pressure respectively). 
TABLE III. STRESS LEVELS BETWEEN THE INTERFACED LAYERS

\begin{tabular}{|c|c|c|c|}
\hline \multirow{2}{*}{ Layer name } & \multicolumn{3}{|c|}{ Vertical Stress (622), kPa } \\
\cline { 2 - 4 } & Case 1 & Case 2 & Case 3 \\
\hline Top of binder & 579.91 & 600.33 & 606.03 \\
Top of base & 195.63 & 240.39 & 268.87 \\
\hline Top of subbase & 40.547 & 22.39 & 14.075 \\
\hline Top of subgrade & 20.071 & 13.14 & 9.4576 \\
\hline
\end{tabular}

The results of this study show that the stress levels at the top of the base layer increased by about 37\% when the thickness of this layer increased from $10 \mathrm{~cm}$ to $30 \mathrm{~cm}$, while the stress levels at the top of the subbase layer decreased by about $64 \%$. By increasing the thickness of the base layer, the stress level was reduced, as shown in Figure 13. Also, the vertical stresses at shallow depths under the tire print slightly vary when the thickness of the base layer increases, but the difference is negligible at large horizontal distance and depth.

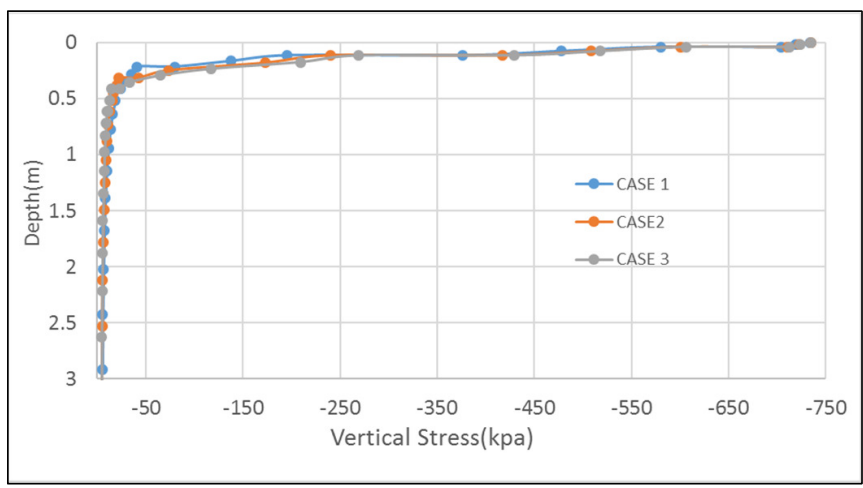

Fig. 13. Vertical stress vs depth.

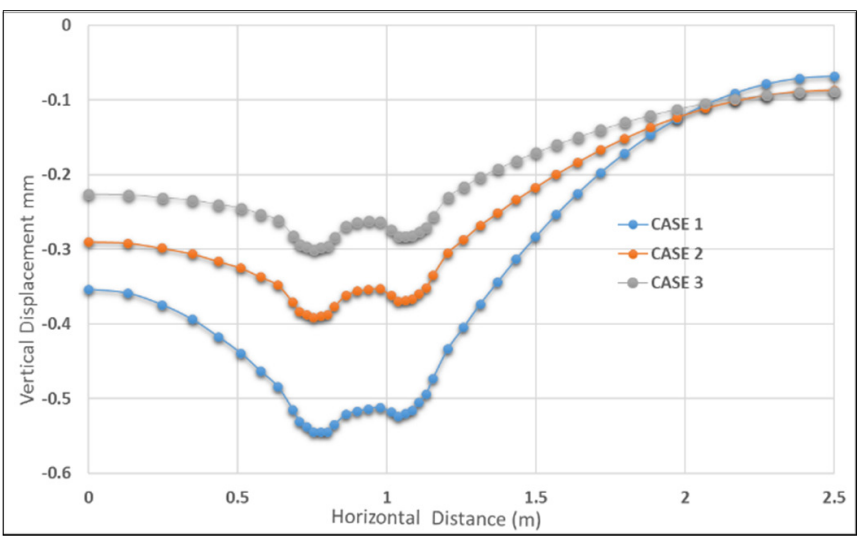

Fig. 14. Vertical displacement on the top of the surface layer.

Figure 14 displays the vertical displacement on the top of the surface layer under the center of the inner wheel with horizontal distance for all cases. When the base layer is increased from 10 to $20 \mathrm{~cm}, 20$ to $30 \mathrm{~cm}$, and 10 to $30 \mathrm{~cm}$ the vertical displacement decreases by $18 \%, 24 \%$, and $37 \%$ respectively. The calculated results from this study are in accordance with those in [15], in which the authors used the ABAQUS to simulate flexible pavements and study the effect of increased base layer thickness on the response of the pavement. The results showed that when the base layer thickness changed from 10 to $30 \mathrm{~cm}$, the deformation on the surface layer reduced by $41 \%$. Authors in [16] studied the effect of the variation of the thickness of the base layer. It was observed that the number of rutting cycles increased by $4.48 \%$ with the change in the thickness of the base layer from $30 \mathrm{~cm}$ to $45 \mathrm{~cm}$. However, the same increase was only $2.47 \%$ when the change in thickness was from $45 \mathrm{~cm}$ to $60 \mathrm{~cm}$. Authors in [17] used the ABAQUS program to study the effect of four thicknesses of the base layer, namely $5,8,10$, and $12 \mathrm{~cm}$ to the elastic and elasto-plastic behavior. The result in the elastic behavior when the thickness of the asphalt changed from 5 to $12 \mathrm{~cm}$ was that the deflection on the top of the layer reduced from 4.1 to $1.2 \mathrm{~mm}$.

\section{CONCLUSION}

The following are the main conclusions based on the results of this study:

- The percentage of the deformation decreases by $37 \%, 18 \%$, and $24 \%$ when the thickness increases from 10 to $30 \mathrm{~cm}$, from 10 to $20 \mathrm{~cm}$, and from 20 to $30 \mathrm{~cm}$ respectively, so the base layer plays the main role in reducing the deformation on the surface layer in the pavement structure.

- The vertical stress on the top of the base layer is 195,240 , and $268 \mathrm{kPa}$ for base layer thickness of 10,20 , and $30 \mathrm{~cm}$ respectively. It decreases to $40.54,22.39$, and $14.07 \mathrm{kPa}$ on the top of the subbase layer corresponding to approximately $20 \%, 9 \%$, and $5 \%$ of the applied stress on the top of the base layer. When the thickness of the base layer increases, the stresses in the layers below the base layer decrease, and thus the stresses above the sub layer decrease.

- It is clear from the study that the vertical stress decreases with the increase in the vertical depth of the all layers. Therefore, the upper layers must be of high quality.

- If the flexible paving layers are too thin, the overall structure of the pavement may disintegrate before the designed life time.

- ABAQUS gives high accuracy in the analysis of multi-layer flexible pavements in addition to the reduction of effort, time, and costs in comparison with the laboratory tests.

\section{REFERENCES}

[1] T. Kumela, "Evaluation of Flexible Pavement Deflections with Respect to Pavement Depths Using Software (A Case Study Jimma to Seka Road)," American Journal of Civil Engineering, vol. 6, no. 5, pp. 141146, Nov. 2018, https://doi.org/10.11648/j.ajce.20180605.11.

[2] E. M. Abd Alla, "The rational use of finite element method in the analysis of flexible pavements," JES. Journal of Engineering Sciences, vol. 34, no. 4, pp. 1185-1211, Jul. 2006, https://doi.org/10.21608/jesaun. 2006.110780.

[3] "Getting Started with ABAQUS/Explicit: Keywords Version (v6.5-1)," Abacus Documentation. https://classes.engineering.wustl.edu/2009/ spring/mase 5513/abaqus/docs/v6.5/books/gsx/default.htm?startat=ch04s 01.html (accessed Nov. 16, 2021).

[4] S. Helwany, J. Dyer, and J. Leidy, "Finite-Element Analyses of Flexible Pavements," Journal of Transportation Engineering, vol. 124, no. 5, pp. 491-499, Sep. 1998, https://doi.org/10.1061/(ASCE)0733-947X(1998) 124:5(491).

[5] M. S. Ranadive and A. B. Tapase, "Parameter sensitive analysis of flexible pavement," International Journal of Pavement Research and 
Technology, vol. 9, no. 6, pp. 466-472, Nov. 2016, https://doi.org/ 10.1016/j.ijprt.2016.12.001.

[6] A. E. A. E.-M. Behiry, "Fatigue and rutting lives in flexible pavement," Ain Shams Engineering Journal, vol. 3, no. 4, pp. 367-374, Dec. 2012, https://doi.org/10.1016/j.asej.2012.04.008.

[7] F. Khodary, H. Akram, and N. Mashaan, "Behaviour of different pavement types under traffic loads using finite element modelling," International Journal of Civil Engineering and Technology, vol. 11, no. 11, pp. 40-48, Nov. 2020, https://doi.org/10.34218/IJCIET.11.11. 2020.004 .

[8] A. Lazizi, H. Trouzine, A. Asroun, and F. Belabdelouhab, "Numerical Simulation of Tire Reinforced Sand behind Retaining Wall Under Earthquake Excitation," Engineering, Technology \& Applied Science Research, vol. 4, no. 2, pp. 605-611, Apr. 2014, https://doi.org/ 10.48084/etasr.427.

[9] A. S. Mahdi and S. D. Mohammed, "Experimental and Numerical Analysis of Bubbles Distribution Influence in BubbleDeck Slab under Harmonic Load Effect," Engineering, Technology \& Applied Science Research, vol. 11, no. 1, pp. 6645-6649, Feb. 2021, https://doi.org/ 10.48084/etasr.3963.

[10] A. H. Abed and A. A. Al-Azzawi, "Evaluation of Rutting Depth in Flexible Pavements by Using Finite Element Analysis and Local Empirical Model," American Journal of Engineering and Applied Sciences, vol. 5, no. 2, pp. 163-169, Aug. 2012, https://doi.org/ 10.3844/ajeassp.2012.163.169.

[11] Y. Huang, Pavement Analysis and Design, 2nd ed. Upper Saddle River, NJ, USA: Pearson, 2003.

[12] P. C. Nguyen, D. D. Pham, T. T. Tran, and T. Nghia-Nguyen, "Modified Numerical Modeling of Axially Loaded Concrete-Filled Steel CircularTube Columns," Engineering, Technology \& Applied Science Research, vol. 11, no. 3, pp. 7094-7099, Jun. 2021, https://doi.org/10.48084/ etasr.4157.

[13] M. T. Rahman, K. Mahmud, and S. Ahsan, "Stress-Strain Characteristics of Flexible Pavement by Finite Element Method," International Journal of Civil and Structural Engineering, vol. 2, no. 1, pp. 233-240, Sep. 2011.

[14] H. Wang and I. L. Al-Qadi, "Evaluation of Surface-Related Pavement Damage due to Tire Braking," Road Materials and Pavement Design, vol. 11, no. 1, pp. 101-121, Jan. 2010, https://doi.org/10.1080/14680629. 2010.9690262

[15] F. Khodary, H. Akram, and A. Othman, "Prediction of Flexible Asphalt Pavement Performances under Material Properties in Variation Influence," International Journal of Advanced Research in Science, vol. 6, no. 12, pp. 11953-11963.

[16] A. B. Tapase and M. S. Ranadive, "Performance Evaluation of Flexible Pavement Using the Finite Element Method," pp. 9-17, Jul. 2016, https://doi.org/10.1061/9780784480090.002.

[17] G. Shafabakhsh, M. Motamedi, and A. Famili, "Influence of asphalt concrete thickness on settlement of flexible pavements," EDJE, vol. 18, pp. 473-483, Jan. 2013. 